GU J Sci, Part C, 6(3): 592-604 (2018)

Gazi Üniversitesi
Fen Bilimleri Dergisi
PART C: TASARIM VE TEKNOLOJI
dergipark.gov.tr/http-gujsc-gazi-edu-tr

\title{
Transformatörlerin Ortalama Sargı Dirençlerinin Gerçek Zamanlı Ölçümü
}

\author{
Cenk GEZEGIN ${ }^{1}$, Hasan DIRIK ${ }^{2, *}$, Muammer ÖZDEMIR ${ }^{3}$ \\ ${ }^{\prime}$ Amasya Üniversitesi, Teknik Bilimler Meslek Yüksekokulu, Elektrik ve Enerji Bölümü, 05186, Merkez/AMASYA \\ ${ }^{I}$ Sinop Üniversitesi, Meslek Yüksekokulu, Elektrik ve Enerji Bölümü, 57000, Merkez/SINOP \\ ${ }^{\text {I} O n d o k u z ~ M a y l s ~ U ̈ n i v e r s i t e s i, ~ M u ̈ h e n d i s l i k ~ F a k u ̈ l t e s i, ~ E l e k t r i k-E l e k t r o n i k ~ M u ̈ h e n d i s l i g ̆ i ~ B o ̈ l u ̈ m u ̈, ~ 55270, ~ K u r u p e l i t / S A M S U N ~}$
}

\begin{abstract}
$\underline{0 ̈ z}$
Makale Bilgisi

Basvuru: 01/02/2018

Düzeltme: $12 / 04 / 2018$

Kabul: $10 / 04 / 2018$

Anahtar Kelimeler

Tek-fazll transformatör

$\ddot{U} c$-fazlı transformatör

Ortalama sargl direnci

Güç sistemlerinin pahalı donanımlarından olan transformatörlerin izlenmesi son yılların önemli konularından biridir. Transformatör izleme sistemleri genellikle arızaların tespiti, transformatör ömrünün belirlenmesi, kayıpların ölçümü ve sarg1 sıcaklıklarının belirlenmesi amaciyla kullanılır. İzlemede kullanılan önemli parametrelerden biri transformatör sargı direncidir. Bu yüzden, bu çalışmada yeni bir sarg1 direnci izleme yöntemi sunulmuştur. Yöntem transformatörlerin eşdeğer devresi ve güç eşitlikleri kullanılarak geliştirilmiştir. Hesaplamalarda transformatörlerin primer ve sekonder tarafı akım ve gerilim değerleri kullanılmaktadır. Böylece transformatörlerin ortalama sargı direncinin gerçek zamanlı izlenmesi sağlanmaktadır. Yöntem tek fazlı transformatörlere uygulanabildiği gibi yıldız-yıldız ve üçgen-yıldız bağlı transformatörler için de kullanılabilmektedir. Bu çalışmada, öncelikle yöntemin matematiksel işlem adımları verilmiştir. Sonrasında Matlab ortamında yapılan benzetim çalışmaları ve iki farklı transformatör üzerinde gerçekleştirilen deneysel çalışmalar verilmiştir. Benzetimler ve deneysel çalışmalar yöntemin geçerliliğini açık bir biçimde ortaya koymuştur.
\end{abstract}

Gerçek zamanlı izleme

\section{Keywords}

Single-phase transformer Three-phase transformer Average winding

resistance

Real time monitoring

\section{Real Time Measurement of Average Winding Resistances of Transformers}

\begin{abstract}
The monitoring of transformers that are expensive equipment of power systems is the one of important issues. Transformer monitoring systems are usually used in order to detect failures, to determine the lifetime, to measure losses and to monitor winding temperatures. One of the important parameters that can be utilized for this aim is the winding resistances of transformer. Therefore, in this work, a novel method for monitoring the winding resistances of transformer is presented. The method is developed with help of equivalent circuit and power equations of transformer. In computations, voltages and currents at the both sides of transformers are used. Thus, it is provided to monitor the average winding resistance of transformer in real time. Not only the method can be applied to single-phase transformer, but also can be used in three-phase transformers with star-star or delta-star connection. In the paper, firstly, mathematical background of the method is introduced. Then, results of simulations done in Matlab environment and experiments are presented. Simulations and experimental works have demonstrated the validity of the method evidently.
\end{abstract}

\section{GÍRIŞ (INTRODUCTION)}

Elektrik güç sistemlerinde kullanılan transformatörler pahalı donanımlar olduğundan sağliklı çalışmalarının sağlanması ve olası arızalarının arıza öncesi evrelerde tespiti ekonomik açıdan önemli bir gerekliliktir. Transformatör durumunun değerlendirmesinde dikkate alınan bazı değişkenler, yăg sızıntıları, yağın seviyesi ve rengi, sargıların elektrik direnci ve kaçak reaktansıdır [1]. Bu değişkenlere dayanan yöntemler genellikle ya gerçek zamanlı izleme sistemlerine uygulanması zordur ya da maliyetli donanımları gerektirir. Bu yüzden transformatörler için düşük maliyetli, kolay monte edilebilen ve gerçek zamanlı çalışabilen izleme ve teşhis sistemlerinin geliştirilmesinin önemi her geçen gün artmaktadır [2]. 
Söz konusu izleme sistemlerinde kullanılabilecek parametrelerden biri de sargıların direncidir. Alternatif akımları taşıyan transformatör sargılarının direnci doğru akım direnci ile aynı değildir. İçerisinden doğru akım (DA) akan bir iletkenin akım yoğunluğu bütün kesiti boyunca aynıdır. Fakat aynı iletkenden akan akımın alternatif akım (AA) olması halinde deri ve yaklaşım etkileri nedeniyle iletkenden akan akımın yoğunluğu diş kısımlarda artarken iç kısımlarda azalır. Bu durum iletkenin etkin direncinin artışına neden olur. Bu artış akan akımların frekansına da bağlı olarak gerçekleşir. Bu direnç iletkenin AA direnci olarak adlandırılır. AA şebekelerinin olmazsa olmazlarından olan transformatörlerin sargılarından akan akımların neden olduğu kayıplar bu yüzden artış gösterir. Dolayısıyla transformatör yük kayıpları (bakır kayıpları) AA sargı direnci ile oldukça yakından ilişkilidir [3-5]. Bu ilişki göz önüne alınarak transformatörlerin daha tasarımı aşamasında AA direnç değerlerinin ve dolayısıyla kayıplarının azaltılmasını amaçlayan iki tane çalışmaya [6] ve [7] nolu kaynaklardan ulaşılabilir. AA sargı direnci aynı zamanda transformatör sargılarının durumu hakkında da önemli bilgiler verir. Transformatör sargılarında oluşan deformasyon ile sargının AA direnci arasında da yakın bir ilişki vardır. Öyle ki transformatörlerin kısa devre empedansı (AA sargı direncini de içerir) üzerinden sargılarının durumunu izlemeye yönelik yazında çok sayıda çalışma bulunmaktadır [8,9]. Söz konusu çalışmalarda AA sargı direncinin yalnızca frekansa bağlı olarak değiştiği varsayılmaktadır. Hâlbuki gerçek zamanlı çalışma esnasında ortaya çıkan sıcaklık artışı nedeniyle DA sargı direncinin ve buna bağlı olarak AA sargı direncinin değişmesi Ayrıca bu değişimin gerçek zamanlı bir biçimde izlenmesi yöntemlerin arıza ve durum tespitinde kullanılabilirliğini arttıracaktır. Bu yüzden bu çalışmada transformatörlerin sarg1 dirençlerinin gerçek zamanlı bir biçimde izlenmesini sağlayan yeni bir yöntem sunulmuştur. Yöntemin kullandığı matematiksel eşitlikler hem tek fazlı hem de üç fazlı transformatörler için bu çalışmada verilmiştir. Yapılan benzetim çalışmaları ve deneysel çalışmalar yöntemin geçerliliğini açık bir biçimde ortaya koymuştur.

\section{TRANSFORMATÖR SARGI DİRENÇLERİ (TRANSFORMER WINDING RESISTANCES)}

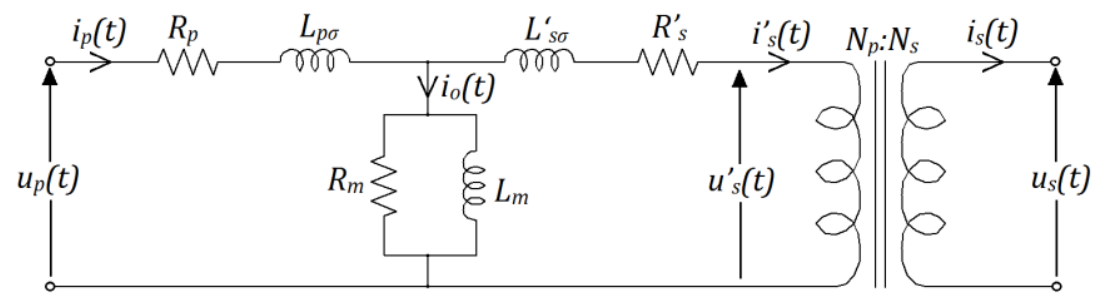

Şekil 1. Tek-fazlı transformatörün T eşdeğer devresi.

Tek fazlı transformatörlerin Şekil 1'de verilmiş olan T eşdeğer devresini göz önüne alalım. Bu eşdeğer devrede yer alan $R_{p}$ ve $R_{s}^{\prime}$ değerleri sırasıyla primerin ve primere indirgenmiş sekonder tarafi dirençlerini temsil etmektedir. $\mathrm{Bu}$ dirençlerin toplamını $R_{w}$ ile gösterecek olursak transformatörün primerinden görünen toplam sargı direnci

$$
R_{w}=R_{p}+R_{s}^{\prime}
$$

eşitliği ile tanımlıdır. Bu çalışmada bu direncin gerçek zamanlı ölçümü amaçlanmakta olup bu değer transformatör sargı sıcaklığının izlenmesinde kullanılabilecek bir parametredir. Burada, sekonder tarafı gerçek sargı direnci $R_{s}$ ile indirgenmiş değeri arasındaki ilişki

$$
R_{s}^{\prime}=t^{2} \cdot R_{s}
$$

eşitliği ile verilir. Bu eşitliklerdeki sarımlar oranı ise $N_{p}$ ve $N_{s}$ primer ve sekonder tarafı sarım sayıları olmak üzere, 


$$
t=N_{p} / N_{s}
$$

eşitliği ile tanımlıdır.

İçerisinden DA taşıyan bir iletkenin akım yoğunluğu bütün kesit boyunca düzgün bir dăğlım göstermesine karşın aynı iletkenin AA taşıması halinde akım yoğunluğu iletkenin bütün kesiti boyunca aynı kalmamaktadır. Bunun temel nedenleri yaklaşım (proximity) ve deri (skin) etkileridir. Bu etkiler iletkenin yüzeyinden merkezine doğru azalan bir akım yoğunluğunun ortaya çıkmasına ve iletkenin etkin olarak kullanılan kesitinde azalmaya neden olmaktadır. Bu da iletkenin AA ve DA taşırken gösterdiği direnç değerlerinin farklı olması anlamına gelmektedir. $\mathrm{Bu}$ fark büyük güçlü transformatörlerin sargılarında yaklaşım ve deri etkilerinin daha fazla olmasından dolayı daha belirgindir. Deri ve yaklaşım etkileri nedeniyle transformatörlerin sarg1 DA direncinin $\left(R_{d c}\right)$ üzerinde meydana gelen artı̧̧a stray direnci $\left(R_{\text {stray }}\right)$ adı verilir. $\mathrm{Bu}$ direncin değeri için aşağıdaki eşitlik geçerlidir.

$$
R_{w}=R_{d c}+R_{\text {stray }}
$$

IEC'e göre ohmik kayıpların dışında kalan Eddy ve diğer stray kayıpları (additional losses) ek kayıplar olarak adlandırılır [10]. Aynı kayıplar IEEE'e göre stray kayıpları $\left(P_{s}\right)$ olarak adlandırılmıştır [11]. Yani, transformatör sargılarının DA direnci nedeniyle ortaya çıkan bakır kayıpları (veya yük kayıpları) omik kayıplar olarak adlandırılırken stray direnci nedeniyle oluşan ek kayıplar stray kayıpları olarak adlandırılır. Bakır kayıpları, sargı akımının $\left(I_{w}\right)$ karesi ile doğru orantılı olarak değişir. Bu yüzden bu kayıplar (2) eşitliği kullanılarak

$$
P_{L L}=I_{w}^{2} \cdot R_{w}
$$

biçiminde yazılabilir. Transformatör kayıpları üzerine yapılan bazı çalışmalar stray kayıplarının bir sonucu olan $R_{\text {stray }}$ direncinin ve dolayısıyla $R_{a c}$ direncinin transformatör sargilarından akan akımın harmonik içeriğine bağlı olarak değiştiğini göstermektedir $[12,13]$. Öyle ki, (5) eşitliğinde gösterilen sargı akımının etkin değerinin aynı olması koşuluyla harmonikli akımın neden olacağı yük kayıpları harmoniksiz durumdaki kayıplardan daha fazla olacaktır. Dolayısıyla $R_{\text {stray }}$ direncinin akımın harmonik içeriğine bağlı olarak değiştiği görülebilir. Bu çalışmada, öncelikle, akımın harmonik bileşenlerinden bağımsız olarak sargı AA dirençlerinin tespiti amaçlandığından sargı akımının yalnızca temel frekans bileşenine karşı düşen direnç değerleri göz önüne alınmıştır. Buna göre akımın ve gerilimin yalnızca temel frekans bileşenleri kullanılarak elde edilecek dirençler için (6) eşitliği yazılabilir.

$$
R_{w 1}=R_{d c}+R_{s t r a y 1}
$$

Son eşitlikteki 1 indisi her bir direncin akımın temel frekans bileşenine karşı gösterdiği direnç olduğunu ifade etmektedir.

\section{TEK FAZLI TRANSFORMATÖRLERIN SARGI DİRENÇLERININ HESAPLANMASI (COMPUTATION OF WINDING RESISTANCES OF SINGLE-PHASE TRANSFORMERS)}

Bilindiği gibi bir iletkende ortaya çıkan güç kaybı, o iletkenden akan akımın karesi ile iletkenin bu akıma karş1 gösterdiği direnç değerinin çarpımına eşittir. Transformatörlerin primer sargıları ile sekonder sargılarını tek bir sarg1 olarak düşünürsek sargıların temel frekansta çektiği toplam güç $\left(P_{L L 1}\right)$, bu sargılardan akan akımların temel bileşenlerinin etkin değerlerinin $\left(\begin{array}{lll}I_{p 1} & \text { ve } & I_{s 1}\end{array}\right)$ kareleri ile temel bileşenlere karşı düşen sargı dirençlerinin ( $R_{p 1}$ ve $R_{s 1}$ ) ayrı ayrı çarpımlarının toplamından bulunabilir: 


$$
P_{L L 1}=R_{p 1} I_{p 1}{ }^{2}+R_{s 1} I_{s 1}^{2}
$$

Dolayısıyla (7) eşitliği indirgenmiş değerler kullanılarak aşağıdaki gibi yeniden yazılabilir.

$$
P_{L L 1}=R_{p 1} I_{p 1}^{2}+R_{s 1}^{\prime} I_{s 1}^{\prime 2}
$$

Son eşitlikteki $I_{p 1}$ ve $I_{s 1}^{\prime}$ değerleri boşta akımın çok küçük olmasından dolayı birbirlerine eşit kabul edilebilir. Her iki akımın ortalama değerini $I_{W 1}$ ile gösterecek olursak, yani,

$$
I_{W 1}=\frac{I_{p 1}+I_{s 1}^{\prime}}{2}
$$

eşitliği ile ifade edersek (8) eşitliği aşağıdaki biçimi ile tekrar yazılabilir.

$$
R_{p 1}+R_{s 1}^{\prime}=\frac{P_{L L 1}}{I_{W 1}^{2}}
$$

Bu eşitlik (5) eşitliğinin yeniden yazılmış biçimidir. (5) eşitliği ile verilmiş olan toplam sargı direnci (6) eşitliğinde primerin ve sekonderin toplam de ve stray dirençleri cinsinden ifade edilmişken (10) eşitliğinde toplam direnç primerin ve sekonderin ayrı ayrı sargı dirençleri cinsinden ifade edilmiştir.

Pratikte transformatör sargılarının çektiği gücün dışında boşta çalışma akımından dolayı da çektiği bir güç vardır. Bu gücün temel frekansta çekilen kısmını $P_{01}$ ile gösterecek olursak transformatörün temel frekanstaki toplam kayıp gücü $\left(P_{T r 1}\right)$ ile boşta kayıp gücü arasındaki fark kullanılarak sargıların kayıp gücü bulunabilir.

$$
P_{L L 1}=P_{T r 1}-P_{01}
$$

Transformatör kayıp gücü ise primerinden verilen güç $\left(P_{p l}\right)$ ile sekonderinden alınan güçler $\left(P_{s l}\right)$ arasındaki farka eşittir.

$$
P_{T r 1}=P_{p 1}-P_{s 1}
$$

Primerden verilen ve sekonderden alınan güçler akım ve gerilim değerleri kullanılarak

$$
\begin{gathered}
P_{p 1}=\operatorname{real}\left(\frac{u_{p 1} \cdot i_{p 1}{ }^{*}}{2}\right) \\
P_{s 1}=\operatorname{real}\left(\frac{u_{s 1} \cdot i_{s 1}{ }^{*}}{2}\right)
\end{gathered}
$$

eşitlikleri ile elde edilebilir. Bu eşitliklerdeki primer ve sekonder tarafı gerilim ve akım değerleri AFD (ayrık fourier dönüşümü) kullanılarak temel bileşenlerinin genlik ve faz açıları cinsinden $u_{p 1}=\sqrt{2} U_{p 1} \angle \alpha_{p 1}, \quad i_{p 1}=\sqrt{2} I_{p 1} \angle \beta_{p 1}, \quad u_{s 1}=\sqrt{2} U_{s 1} \angle \alpha_{s 1} \quad$ ve $i_{s 1}=\sqrt{2} I_{s 1} \angle \beta_{s 1} \quad$ biçiminde elde edilmiş değerlerdir. (11) eşitliğindeki boşta kayıp güç değeri ise boşta akım $i_{01}$ ve eşdeğer devredeki orta nokta gerilimi $\left(u_{m}\right)$ kullanılarak (15) ile bulunabilir. 


$$
P_{01}=\operatorname{real}\left(\frac{u_{m 1} \cdot i_{01}^{*}}{2}\right)
$$

$\mathrm{Bu}$ akım ve gerilim değerleri ise sırasıyla

$$
\begin{gathered}
u_{m 1}=\frac{u_{p 1}+u_{s 1}^{\prime}}{2} \\
i_{01}=i_{p 1}-i_{s 1}^{\prime}
\end{gathered}
$$

eşitlikleri ile elde edilebilir. Şekil 2'de bu bölümde anlatılmış olan ve gerçek zamanlı akım ve gerilim verilerinden sargı direncini hesaplamayı sağlayan bu yöntemin blok diyagramı verilmiştir.

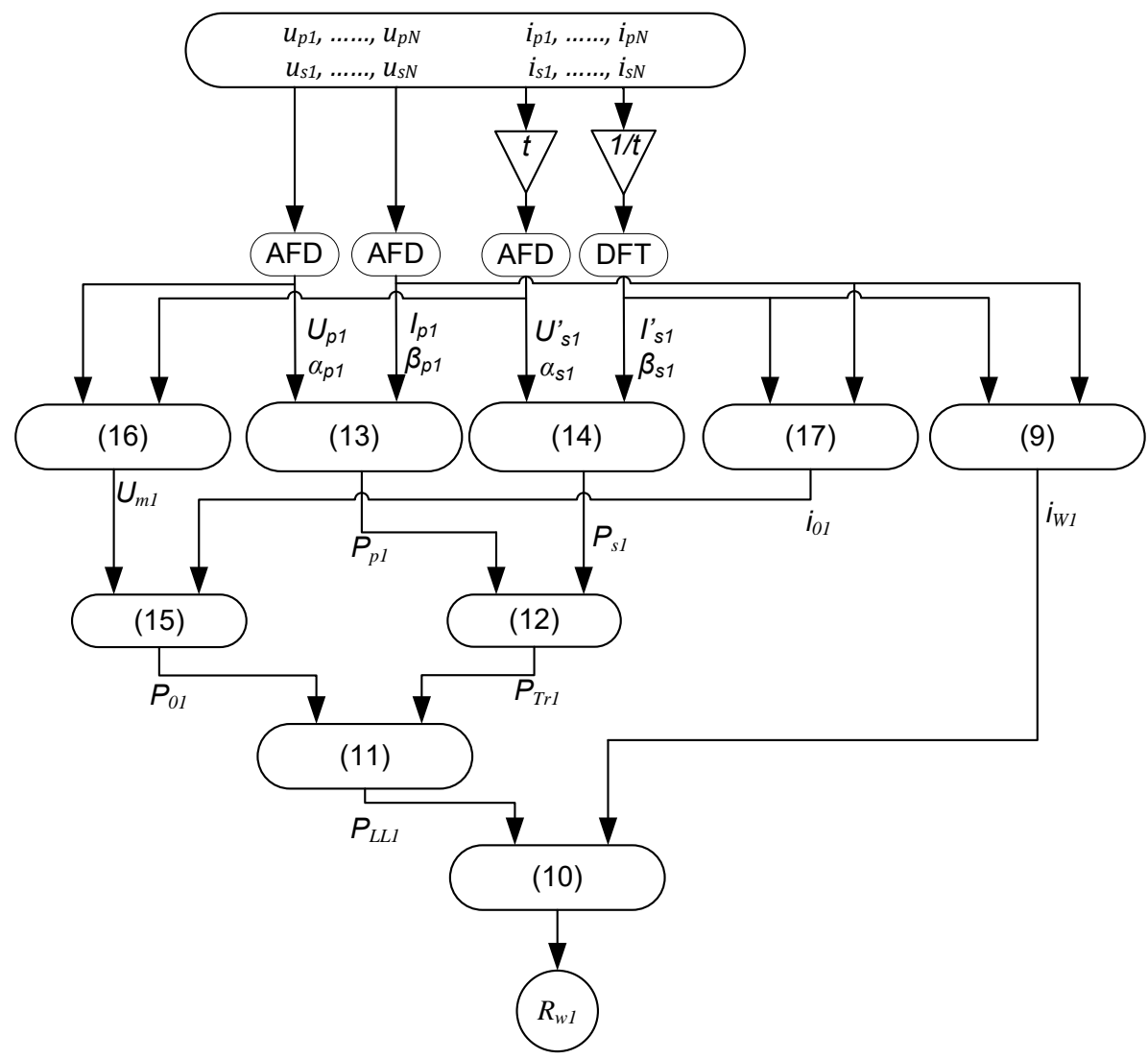

Şekil 2. Tek fazlı transformatörler için sargı direnci elde etme yönteminin blok şeması.

\section{4. ÜÇ FAZLI TRANSFORMATÖRLERIN SARGI DİRENÇLERINIIN HESAPLANMASI (COMPUTATION OF WINDING RESISTANCES OF SINGLE-PHASE TRANSFORMERS)}

Üç-fazlı transformatörlerin her bir bacağındaki primer ve sekonder sargıları tek-fazlı transformatörlerde olduğu gibi aynı manyetik akıya maruz kaldığından bir üç-fazlı transformatörün her bir bacağı bir tekfazlı transformatör olarak göz önüne alınabilir. Pratikte 3-fazlı transformatörlerin her bir sargısından akan akımı ve sargı üzerindeki gerilimi ölçmek her zaman mümkün değildir. Doğru hesaplama için her bir sargının akımı ve gerilimi kullanılmalıdır. Yıldız bağlı sargılarda hat akımları sargı akımlarına eşit olup doğrudan ölçülebildiği halde üçgen bağlı sargılarda bu mümkün değildir. Benzer şekilde, üçgen bağlantılı sargılarda faz-faz gerilimi aynı zamanda sargı gerilimine eşitken yıldız noktası dışarı çıkarılmamış olan yıldız bağlı sargılarda sargı gerilimini doğrudan ölçmek de mümkün değildir. Bu yüzden, bu kısımda, transformatörün hat akımları ve faz-faz gerilimleri üzerinden AA sarg1 direncinin nasıl elde edileceği üzerinde de durulmuştur. Bunun için sıklıkla kullanılan Yy ve Dy bağlantılı iki farklı transformatör göz 
önüne alınmıştır. Her iki bağlantı grubu için transformatörlerin sargı bağlantı yapısı Şekil 3’te verilmiştir. Burada verilen eşitliklerde transformatörlerin primerinden ve sekonderinden ölçülen gerilimlerin ve akımların öncelikle AFD ve transformatör dönüştürme oranları kullanılarak $u_{A C 1}=\sqrt{2} U_{A C 1} \angle \alpha_{A C 1}$, $u_{B C 1}=\sqrt{2} U_{B C 1} \angle \alpha_{B C 1}, \quad u_{a c 1}^{\prime}=\sqrt{2} U_{a c 1} \angle \alpha_{a c 1}, \quad u_{b c 1}^{\prime}=\sqrt{2} U_{b c 1} \angle \alpha_{b c 1}, \quad i_{A 1}=\sqrt{2} I_{A 1} \angle \beta_{A 1}, \quad i_{B 1}=\sqrt{2} I_{B 1} \angle \beta_{B 1}$, $i_{a 1}^{\prime}=\sqrt{2} I_{a 1}^{\prime} \angle \beta_{a 1}$ ve $i_{b 1}^{\prime}=\sqrt{2} I_{b 1}^{\prime} \angle \beta_{b 1}$ biçimlerine dönüştürüldüğü varsayılmıştır.

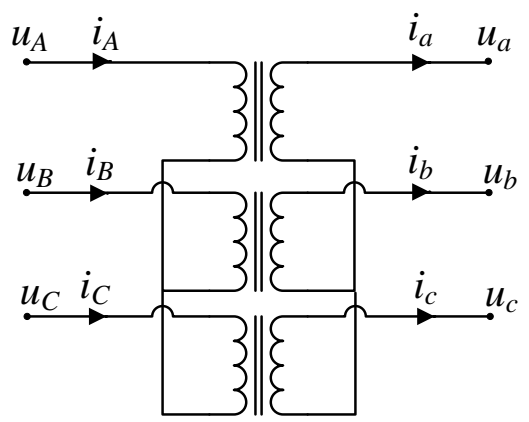

(a)

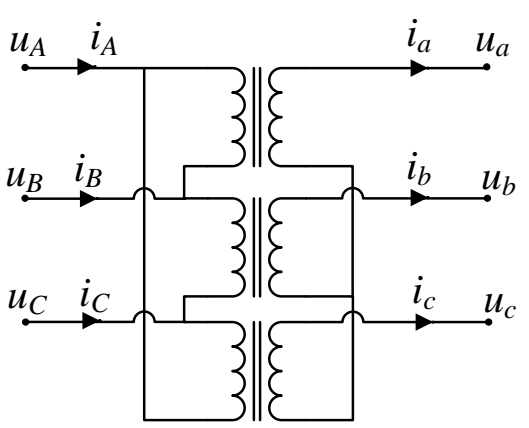

(b)

Şekil 3. Yy ve Dy bağlantı grubuna sahip transformatörlerin sargı bağlantı yapısı.

\section{A. Yıldız-Yıldız Bağlı Transformatörler (Star-Star Connected Transformers)}

Eşdeğer devre yapısı Şekil 3-a'da verilmiş olan Yy bağlı transformatörün her bir bacağını bir tek fazlı transformatör olarak göz önüne alabiliriz. Eğer, her bir bacağı bir tek-fazlı transformatör olarak düşünürsek tek fazlı transformatörler için kullanılan eşitliklerin benzeri burada da kullanılabilir. Buna göre, transformatörün her bir bacağındaki sarg1 güç kayıpları $\left(P_{L L A l}, P_{L L B l}\right.$ ve $\left.P_{L L C l}\right)$, ilgili sargıların toplam gerilim düşümleri ile akımlarının eşleniklerinin çarpımına eşit olacaktır. Burada tek fazlı transformatörlerde olduğu gibi daha doğru bir sonuç için primer ve primere indirgenmiş sekonder tarafi akımlarının ortalaması kullanılmıştır.

$$
\begin{aligned}
& P_{L L A 1}=\operatorname{Re} a l\left[\left(u_{A N 1}-u_{a n 1}^{\prime}\right)\left(\frac{i_{A 1}+i_{a 1}^{\prime}}{2}\right)^{*}\right] \\
& P_{L L B 1}=\operatorname{Re} a l\left[\left(u_{B N 1}-u_{b n 1}^{\prime}\right)\left(\frac{i_{B 1}+i_{b 1}^{\prime}}{2}\right)^{*}\right] \\
& P_{L L C 1}=\operatorname{Re} a l\left[\left(u_{C N 1}-u_{c n 1}^{\prime}\right)\left(\frac{i_{C 1}+i_{c 1}^{\prime}}{2}\right)^{*}\right]
\end{aligned}
$$

Bu durumda transformatör sargılarında kaybolan güç için (21) eşitliği geçerli olacaktır.

$$
P_{L L 1}=\frac{1}{2} \operatorname{Re} a l\left[\left(u_{A N 1}-u_{a n 1}^{\prime}\right)\left(i_{A 1}+i_{a 1}^{\prime}\right)^{*}+\left(u_{B N 1}-u_{b n 1}^{\prime}\right)\left(i_{B 1}+i_{b 1}^{\prime}\right)^{*}+\left(u_{C N 1}-u_{c n 1}^{\prime}\right)\left(i_{C 1}+i_{c 1}^{\prime}\right)^{*}\right]
$$

$\mathrm{Bu}$ eşitlik yeniden yazılarak düzenlenirse son olarak

$$
P_{L L 1}=\frac{1}{2} \operatorname{Re} a l\left[\left(u_{A C 1}-u_{a c 1}^{\prime}\right)\left(i_{A 1}+i_{a 1}^{\prime}\right)^{*}+\left(u_{B C 1}-u_{b c 1}^{\prime}\right)\left(i_{B 1}+i_{b 1}^{\prime}\right)^{*}\right]
$$

elde edilir. Primer tarafından görünen akımların karelerinin ortalaması ise aşağıdaki eşitlikle hesaplanır. 


$$
I_{p 1}^{2}=\frac{I_{A 1}{ }^{2}+I_{a 1}^{\prime}{ }^{2}+I_{B 1}{ }^{2}+I_{b 1}^{\prime}{ }^{2}+I_{C 1}{ }^{2}+I_{c 1}^{\prime}{ }^{2}}{6}
$$

Son olarak (22) ve (23)'teki sonuçlar (24) eşitliğinde yerine yazılarak transformatörün ortalama sarg1 direnci hesaplanırsa (25) ile verilen sonuca ulaşılmış olur.

$$
\begin{gathered}
R_{w 1}=\frac{P_{L L 1}}{3 I_{p 1}{ }^{2}} \\
R_{w 1}=\frac{\operatorname{Re}\left[\left(u_{A C 1}-u_{a c 1}^{\prime}\right)\left(i_{A 1}+i_{a 1}^{\prime}{ }^{*}\right)^{*}+\left(u_{B C 1}-u_{b c 1}{ }_{b c 1}\right)\left(i_{B 1}+i_{b 1}{ }^{\prime}\right)^{*}\right]}{I_{A 1}{ }^{2}+I_{B 1}{ }^{2}+I_{C 1}{ }^{2}+I_{a 1}{ }^{2}+I_{b 1}^{\prime}{ }^{2}+I_{c 1}^{\prime}{ }^{2}}
\end{gathered}
$$

Son eşitlikteki $I_{C 1}$ ve $I_{c 1}$ akımları

$$
\begin{gathered}
i_{C 1}=-\left(i_{A 1}+i_{B 1}\right) \\
i_{c 1}=-\left(i_{a 1}+i_{b 1}\right) \\
i_{C 1}=I_{C 1} \angle \beta_{C 1} \\
i_{c 1}=I_{c 1} \angle \beta_{c 1}
\end{gathered}
$$

eşitlikleri ile elde edilebilmektedir. (25) eşitliğinin kullanılabilmesi için transformatörün primerinden ve sekonderinden $u_{A C}, u_{B C}, u_{a c}, u_{b c}$ gerilimlerinin ve $i_{A}, i_{B}, i_{a}, i_{b}$ akımlarının eş-zamanlı ölçülmesi yeterlidir. Şekil 4 'te bu kısımda anlatılan yöntemin blok şeması verilmiştir.

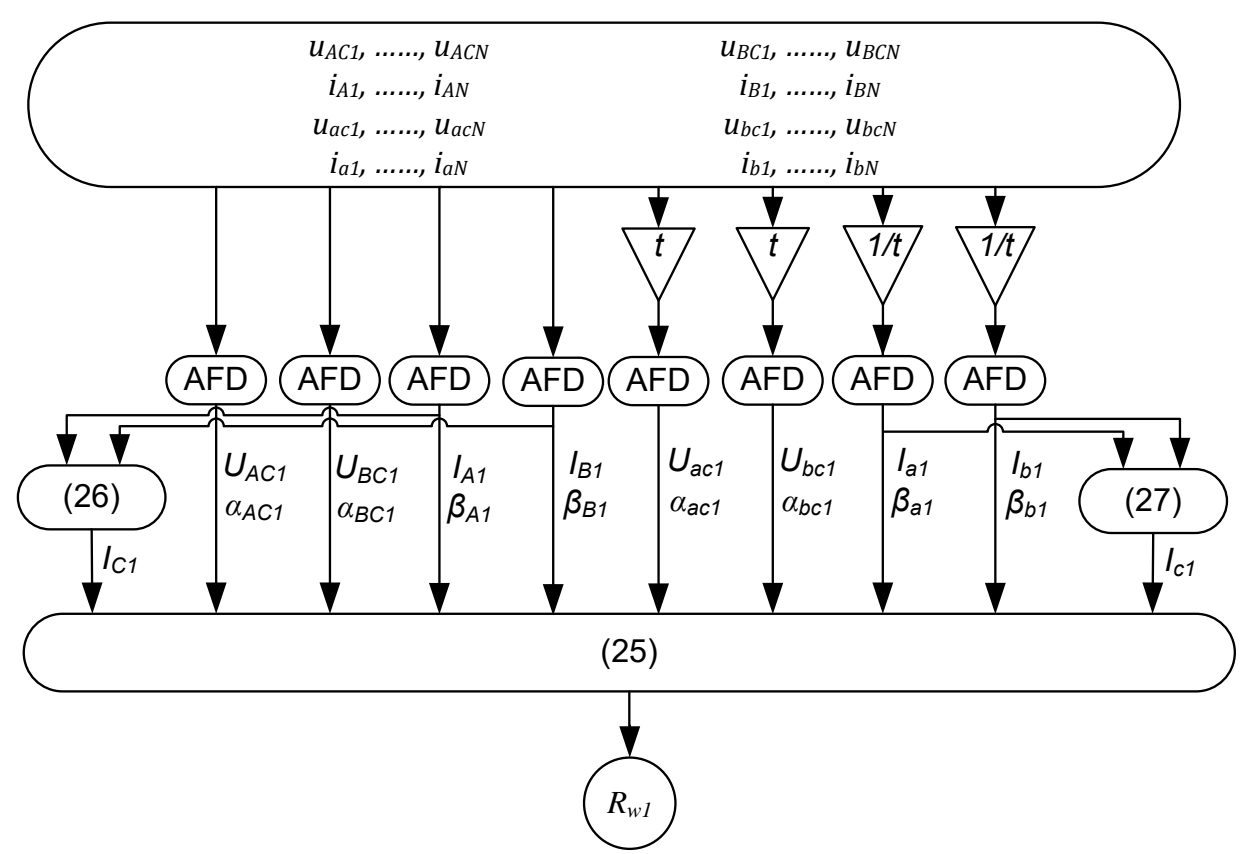

Şekil 4. Yy bağlantılı transformatörün sargı direnci elde etme yönteminin blok şeması.

B. Üçgen-Yıldız Bağlı Transformatörler (Delta-Star Connected Transformers)

Şekil 3-b'de verilmiş olan üçgen-yıldız bağlı transformatör devresini göz önüne alalım. Sargıları bu şekilde bağlı olan transformatörlerin üçgen bağlı tarafta sargı akımlarını ölçmek mümkün değildir. Ayrıca 
hat akımları kullanılarak sargı akımlarının elde edilebilmesi de mümkün değildir. Bu yüzden sekonder tarafı akımları sargı akımlarına eşit olduğundan bu akımlar primer tarafı hat akımlarına indirgenmiştir. Primer tarafı hat akımları ile sekonder tarafı akımlarının indirgenmiş değerleri arasındaki fark ilgili bacağın mıknatıslanma akımının $\sqrt{3}$ katı kadar olacaktır. Bu yüzden Dy bağlı transformatörün toplam demir kayıpları $\left(P_{m 1}\right)$ için aşağıdaki eşitlik yazılabilir.

$$
P_{m 1}=\frac{1}{\sqrt{3}} \operatorname{real}\left[\begin{array}{l}
\frac{u_{A B 1}+u_{a n 1}^{\prime}}{2}\left(i_{A 1}-\left(i_{a 1}^{\prime}-i_{c 1}^{\prime}\right)\right)^{*}+\frac{u_{B C 1}+u_{b n 1}^{\prime}}{2}\left(i_{B 1}-\left(i_{b 1}^{\prime}-i_{a 1}^{\prime}\right)\right)^{*} \\
+\frac{u_{C A 1}+u_{c n 1}^{\prime}}{2}\left(i_{C 1}-\left(i_{c 1}^{\prime}-i_{b 1}^{\prime}\right)\right)^{*}
\end{array}\right]
$$

Bu eşitlik ölçülen akımlar ve gerilimler cinsinden düzenlenerek yeniden yazılırsa (31) eşitliği bulunur.

$$
P_{m 1}=\frac{1}{2 \sqrt{3}} \operatorname{real}\left[\begin{array}{l}
\left(u_{A C 1}-u_{B C 1}\right)\left(i_{A 1}-2 i^{\prime}{ }_{a 1}-i_{b 1}^{\prime}\right)^{*}+u_{B C 1}\left(i_{B 1}-i_{b 1}^{\prime}+i^{\prime}{ }_{a 1}\right)^{*} \\
+u_{A C 1}\left(i_{A 1}+i_{B 1}-i^{\prime}{ }_{a 1}-2 i^{\prime}{ }_{b 1}\right)^{*}+u_{a c 1}\left(i_{A 1}-2 i^{\prime}{ }_{a 1}-i_{b 1}{ }^{\prime}\right)^{*}+u_{b c 1}\left(i_{B 1}+i_{a 1}^{\prime}{ }_{a 1}-i_{b 1}^{\prime}\right)^{*}
\end{array}\right]
$$

Öte yandan transformatörün toplam kayıpları primerinden verilen güç ile sekonderinden alınan güç arasındaki fark kullanılarak (32) eşitliği biçiminde yazılabilir.

$$
P_{k}=\operatorname{real}\left[u_{A C 1} i_{A 1}{ }^{*}+u_{B C 1} i_{B 1}{ }^{*}-u_{a c 1} i_{a 1}{ }^{*}+u_{b c 1} i_{b 1}{ }^{*}\right]
$$

Transformatörün toplam kayıplarından demir kayıpları çıkarılırsa yük kayıpları elde edilecektir.

$$
P_{L L 1}=P_{k 1}-P_{m 1}
$$

Transformatörün mıknatıslanma akımı ihmal edilirse sargı akımlarının karelerinin ortalaması

$$
I_{p 1}^{2}=\frac{I_{a 1}^{\prime}{ }^{2}+I_{b 1}^{\prime}{ }^{2}+I_{c 1}^{\prime}{ }^{2}}{3}
$$

olacaktır. Bu eşitlikteki $I_{c 1}^{\prime}$ değeri (27) ve (29) eşitlikleri ile elde edilebilir. Sonuç olarak, son iki eşitlik kullanılarak primerden görünen ortalama sargı direnci aşağıdaki gibi hesaplanabilir.

$$
R_{w}=\frac{P_{L L 1}}{3 I_{p 1}^{2}}
$$

Bu bölümde Dy bağlantılı 3-fazlı transformatörler için anlatılmış olan gerçek zamanlı sargı direnci hesaplama yönteminin blok şeması Şekil 5'te özet olarak verilmiştir. 


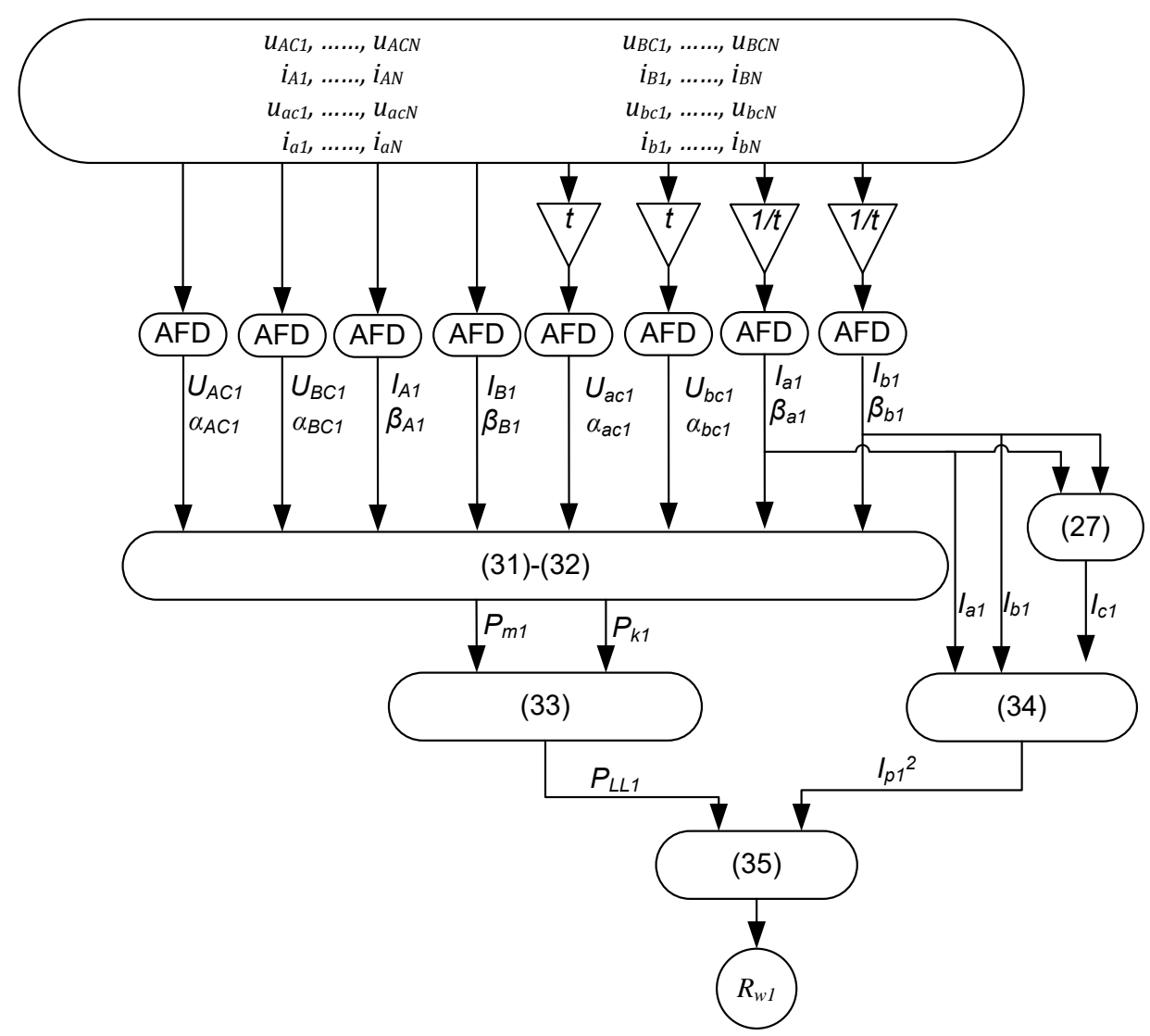

Şekil 5. Dy bağlantılı transformatörün sargı direnci elde etme yönteminin blok şeması.

\section{BENZETIMLER VE DENEYSEL ÇALIŞMALAR (SIMULATIONS AND EXPERIMENTAL WORKS)}

Bu bölümde geliştirilmiş olan yöntemin öncelikle Matlab/Simulink ortamındaki doğrusal transformatör modelleri üzerinde yapılmış olan benzetim ve deneysel çalı̧̧malarının sonuçları verilmiştir. Benzetim çalışmalarında kullanılan transformatörlerin anma değerleri Tablo I'de verilmiştir.

Tablo I. Benzetimlerde kullanılan transformatörlerin anma değerleri.

\begin{tabular}{|c|c|c|c|}
\hline & Transformatör-1 & Transformatör-2 & Transformatör-3 \\
\hline Faz sayısı & 1 & 3 & 3 \\
\hline Bağlantı biçimi & - & Yy & Dy \\
\hline$S$ & $1 \mathrm{kVA}$ & $10 \mathrm{kVA}$ & $10 \mathrm{kVA}$ \\
\hline$U_{p}-U_{s}$ & $220 \mathrm{~V}-380 \mathrm{~V}$ & $380 \mathrm{~V}-190 \mathrm{~V}$ & $380 \mathrm{~V}-190 \sqrt{3} \mathrm{~V}$ \\
\hline$I_{p}-I_{s}$ & $4,55 \mathrm{~A}-2,62 \mathrm{~A}$ & $26,3 \mathrm{~A}-52,6 \mathrm{~A}$ & $26,3 \mathrm{~A}-30,4 \mathrm{~A}$ \\
\hline$R_{p}-R_{s}$ & $0,2 \Omega-0,3 \Omega$ & $0,04 \Omega-0,01 \Omega$ & $0,02 \Omega-0,01 \Omega$ \\
\hline$L_{\sigma p}-L_{\sigma s}$ & $2 \mathrm{mH}-3 \mathrm{mH}$ & $4 \mathrm{mH}-1 \mathrm{mH}$ & $2 \mathrm{mH}-1 \mathrm{mH}$ \\
\hline$R_{m}-L_{m}$ & $400 \Omega-10 \mathrm{H}$ & $600 \Omega-15 \mathrm{H}$ & $600 \Omega-15 \mathrm{H}$ \\
\hline
\end{tabular}

Transformatörler sekonder taraflarına $5 \Omega$ 'luk direnç yükü bağlanarak benzetimi yapılmıştır. Her bir transformatör için yapılan toplamda 0,3 saniyelik benzetimin ilk 0,1 saniyesi boyunca saf sinüzoidal, ikinci 0,1 saniyelik zaman boyunca harmonikli bir gerilim kullanılmıştır. Son 0,1 saniye boyunca ise gerilimin genliği harmonikler dâhil $\% 10$ oranında arttırılarak uygulanmıştır. Normalde tek fazlı transformatör için ölçülmesi gereken toplam sargı direnci değeri $0,2+0,3 \times(220 / 380)^{2}=0,3006 \Omega$ olmalıdır. Benzetim boyunca elde edilen direncin değişimi ise Şekil 6'da verilmiştir. Aynı şekilde transformatörün primerine uygulanan gerilim ve primer akımının değişimleri de verilmiştir. Bu şekilden de anlaşılacağı üzere yöntem transformatörün akımı ve gerilimi değişse bile toplam sargı direncini başarılı bir biçimde 
hesaplayabilmektedir. Bu çalışmada kullanılan yöntemde gerilimlerin ve akımların son 1 temel periyod boyunca alınan örnekleme değerleri AFD hesaplamalarında kullanılmakta ve gerilim ve akımların temel bileşen genlik ve açıları hesaplanmaktadır. Yani, temel bileşen hesabı bir kayan pencereli AFD ile yapılmaktadır. Bu durum, gerilimde veya akımda meydana gelecek ani değişimlerin kayan pencere içerisinde yer alan örnekleme verileri arasında uyumsuzluk yaratmasına ve 1 temel periyodluk geçici hatalı hesaplamaların oluşmasına neden olmaktadır. Bu etki nedeniyle benzetimin $0 \mathrm{~s}, 0,1 \mathrm{~s}$ ve $0,2 \mathrm{~s}$ anlarında geçici hatalar oluşmuştur.

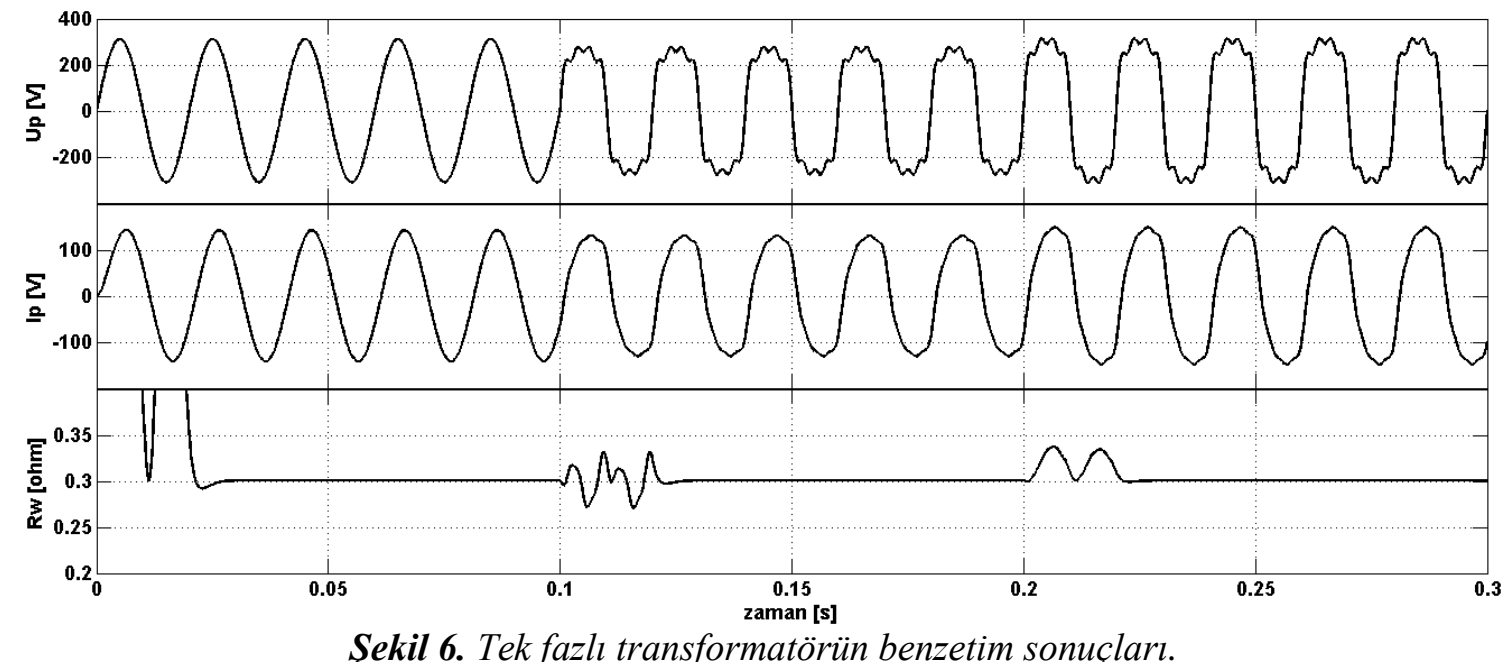

Benzer şekilde Yy ve Dy bağlı transformatörlerin de benzetimi yapılmıştır. Yy bağlı transformatörün elde edilmesi gereken toplam direnç değeri $0,04+0,01 \times(380 / 190)^{2}=0,08$ $\Omega$ 'dur. Şekil 7'de benzetim sonucunda elde edilen toplam sargı direncinin değişimi görülmektedir. Aynı şekilde transformatörün primer tarafı a-c fazları arası gerilimi ve a fazı akımı görülmektedir.

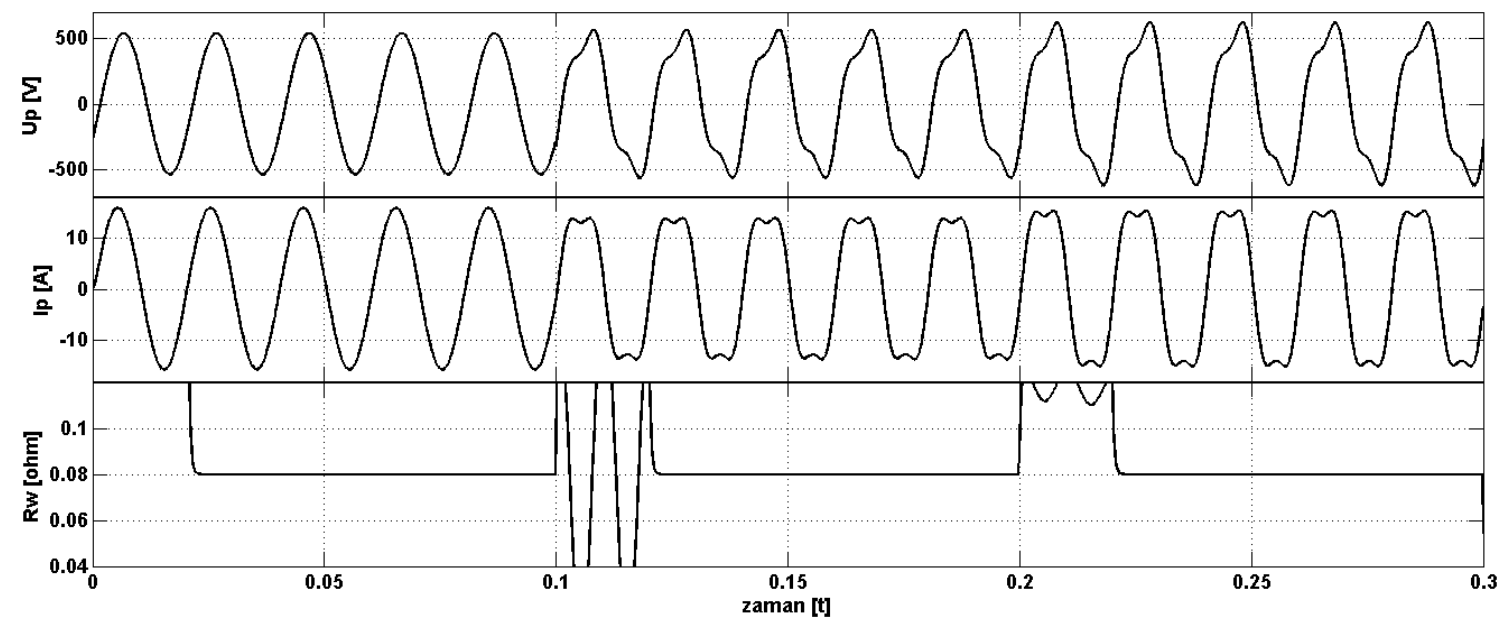

Şekil 7. Yy bağlı üç fazlı transformatörün benzetim sonuçları.

Dy bağl1 transformatörün elde edilmesi gereken toplam direnç değeri $0,02+0,01 \times(380 / 190)^{2}=0,06 \Omega$ 'dur. Şekil 8'de benzetim sonucunda elde edilen toplam sargı direncinin değişimi görülmektedir. Aynı şekilde transformatörün primer tarafı a-c fazları arası gerilimi ve a fazı akımı görülmektedir. 


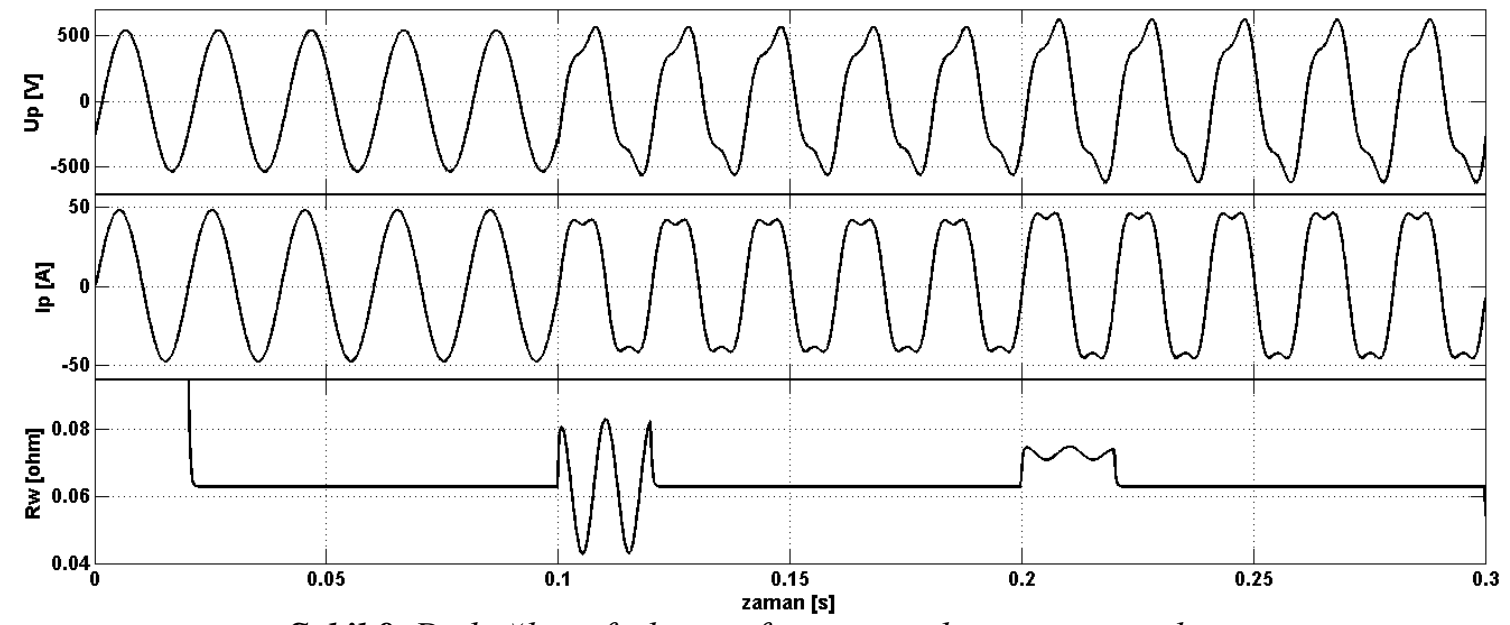

Şekil 8. Dy bă̆lı üç fazlı transformatörün benzetim sonuçları.

Şekil 6-8'deki sonuçlar yöntemin toplam sargı direncini gerçek zamanlı bir biçimde doğru olarak hesaplayabildiğini göstermektedir. Yalnız, Şekil 8'deki sonuçlar çok az bir hata içermektedir. DY bağlı transformatörün primerinden görünen toplam sargı direnci gerçekte $0,06 \Omega$ olmasına karşın bu değer benzetim sonucunda $0.0629 \Omega$ olarak elde edilmiştir. Yapılan hata \%4.8'dir. Bunun nedeninin primer sarg1 akımlarının hesaplamalarda kullanılmaması olduğu düşünülmektedir. Yine de yapılan hata çok küçük olup ihmal edilebilir. Sarg1 direncinin Şekil 6'da gözlenen geçici değişimi Şekil 7 ve 8'de de görülmektedir. Bunun nedeninin daha önce de açıklandığı üzere kullanılan 1 temel periyod genişliğine sahip kayan penceredeki gerilim ve akım örneklerinin geçici değişim nedeniyle uyumsuzluğa düşmesidir. $\mathrm{Bu}$ değişim 1 temel periyod sonunda tekrar normale dönmektedir.

$\mathrm{Bu}$ çalışmada açıklanan yöntem biri tek fazlı diğeri de üç fazlı olmak üzere iki tane transformatör üzerinde deneysel olarak test edilmiştir. Deneysel çalışmaların biri tek fazlı transformatör üzerinde yapılırken diğer ikisi üç fazlı transformatörün sargıları Yy ve Dy biçiminde bağlanarak gerçekleştirilmiştir. Deneysel çalışmalar, transformatörlerin sargı dirençlerinin önerilen yöntemin (yükte çalışmada iken) yanında kısa devre testleri ile elde edilmesi ve mikro-ohm-metre ile doğrudan ölçümünden oluşmaktadır. Deneysel çalışmalarda kullanılan transformatörlerin anma değerleri Tablo II'de verilmiştir. Deneysel çalışma düzeneğinin görünümü de Şekil 9'da verilmiştir. Bu düzenekte, bir oto-transformatörün çıkışından alınan gerilim transformatörün primerine uygulanmaktadır. Transformatörün sekonderine ise yükte çalışma testleri için bir omik yük grubu bağlanırken kısa devre çalışma durumunda bu uçlar bir kontaktör üzerinden kısa devre edilmektedir.

Tablo II. Deneysel çalışmalarda kullanılan transformatörlerin anma değerleri.

\begin{tabular}{|c|c|c|}
\hline & Transformatör-1 & Transformatör-2 \\
\hline Faz say1s1 & 1 & 3 \\
\hline$S$ & $5 \mathrm{kVA}$ & $15 \mathrm{kVA}$ \\
\hline$U_{p}-U_{s}$ & $380 \mathrm{~V}-220 \mathrm{~V}$ & $380 \mathrm{~V}-220 \mathrm{~V}$ \\
\hline$N_{p}-N_{s}$ & $150-90$ & $234-138$ \\
\hline$I_{p}-I_{s}$ & $13,2 \mathrm{~A}-22,7 \mathrm{~A}$ & $22,7 \mathrm{~A}-39,4 \mathrm{~A}$ \\
\hline
\end{tabular}




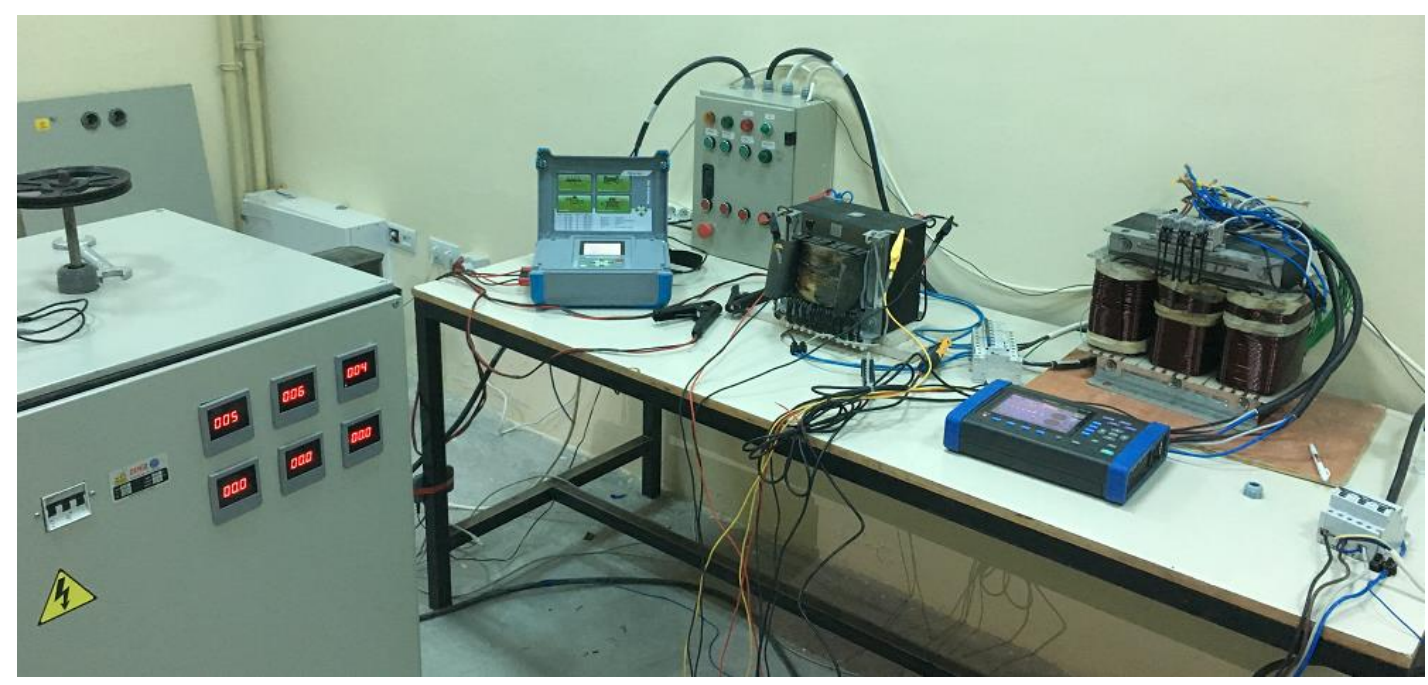

Şekil 9. Deneysel çalışmalarda kullanılan deney düzeneğinin ve transformatörlerin görünümü.

Kısa devre testi sonucunda elde edilen veriler klasik yöntemle işlenerek toplam sargı dirençleri elde edilmiştir. Yükte çalışma testi verileri ise yukarıda anlatılan yöntemler kullanılarak işlenmiş ve toplam sarg1 dirençleri elde edilmiştir. Deneylerde kullanılan transformatörlerin primer ve sekonder sargı dirençleri bir mikro-ohm-metre yardımıyla deneylerden önce ölçülerek sargıların toplam DC dirençleri (1) ve (2) eşitlikleri kullanılarak elde edilmiştir. Elde edilen sonuçlar Tablo III.'te özet olarak verilmiştir.

Tablo III. Deneysel çalışmalar sonucunda elde edilen direnç değerleri.

\begin{tabular}{|c|c|c|c|}
\hline & Transformatör-1 & Transformatör-2 (Yy) & Transformatör-2 (Dy) \\
\hline $\begin{array}{c}R_{p}-R_{s} \text { (mikro-ohm-metre } \\
\text { ile ölçülen) }\end{array}$ & $247,6 \mathrm{~m} \Omega-106,1 \mathrm{~m} \Omega$ & $349,5 \mathrm{~m} \Omega-141,4 \mathrm{~m} \Omega$ & $349,5 \mathrm{~m} \Omega-141,4 \mathrm{~m} \Omega$ \\
\hline$R_{d c}$ & $542,3 \mathrm{~m} \Omega$ & $756,1 \mathrm{~m} \Omega$ & $756,1 \mathrm{~m} \Omega$ \\
\hline$R_{w l}$ (k1sadevre yöntemi) & $537,7 \mathrm{~m} \Omega$ & $745,4 \mathrm{~m} \Omega$ & $742,3 \mathrm{~m} \Omega$ \\
\hline$R_{w l}$ (önerilen yöntem) & $538,1 \mathrm{~m} \Omega$ & $767,5 \mathrm{~m} \Omega$ & $760,3 \mathrm{~m} \Omega$ \\
\hline
\end{tabular}

Sonuçlara göre her üç transformatörün ortalama sargı dirençleri yaklaşık olarak eşit değerlerde elde edilmiştir. Kısa devre deneyleri ile elde edilen değerler bu çalışmada önerilen ve yükte çalışma verisi ile elde edilen değerler ile hemen hemen aynıdır. Bu da tek ve üç fazlı transformatörlerin ortalama sargı dirençlerinin sunulan yöntem ile başarılı bir biçimde elde edilebileceğini göstermektedir.

\section{SONUÇLAR (CONCLUSION)}

$\mathrm{Bu}$ çalışmada tek ve üç fazlı transformatörlerin ortalama sargı dirençlerinin gerçek zamanlı ölçümler kullanılarak nasıl elde edileceği açıklanmıştır. Önerilen yöntem transformatörlerin eşdeğer devresi ve güç eşitlikleri kullanılarak geliştirilmiştir. Stray kayıplarından dolayı sargıların doğru akımdaki direnci ile alternatif akımdaki direnci arasında bir fark oluşur. Bu fark uygulanan alternatif gerilimin frekansı ile de ilişkili olduğundan sargıların direnci akımların ve gerilimlerin yalnızca temel frekans bileşenleri kullanılarak elde edilmiştir. Yapılan kısa devre deneyleri ile yükte çalışma deneylerinden elde edilen sargı dirençlerinin çok yakın olması önerilen yöntemin başarılı olduğunu göstermektedir. Benzetim çalışmalarının sonuçları da bunu desteklemektedir. 


\section{KAYNAKLAR (REFERENCES)}

[1] F. O. Fernández, A. Ortiz, F. Delgado, I. Fernández, A. Santisteban and A. Cavallini, Transformer health indices calculation considering hot-spot temperature and load index, IEEE Electrical Insulation Magazine, 33: 2 (2017) 35-43.

[2] G. Hipszki, R. Schmid and R. Maier, Distribution transformers - ready for the smart grid, 21st International Conference on Electricity Distribution, Paper 1121, Frankfurt, pp. 1-4, (2011).

[3] M. Sippola and R. E. Sepponen, Accurate prediction of high-frequency power-transformer losses and temperature rise, IEEE Transactions on Power Electronics, 17: 5 (2002) 835-847.

[4] I. Villar, U. Viscarret, I. Etxeberria-Otadui and A. Rufer, Global loss evaluation methods for nonsinusoidally fed medium-frequency power transformers, IEEE Transactions on Industrial Electronics, 56: 10 (2009) 4132-4140.

[5] M. A. Taher, S. Kamel and Z. M. Ali, K-Factor and transformer losses calculations under harmonics, Eighteenth International Middle East Power Systems Conference (MEPCON), Cairo, pp. 753-758, (2016).

[6] P. Thummala, H. Schneider, Z. Ouyang, Z. Zhang and M. A. E. Andersen, Estimation of transformer parameters and loss analysis for high voltage capacitor charging application, IEEE ECCE Asia Downunder, Melbourne, VIC, pp. 704-710, (2013).

[7] A. Pereira, B. Lefebvre, F. Sixdenier, M. A. Raulet and N. Burais, Comparison between numerical and analytical methods of $\mathrm{AC}$ resistance evaluation for medium frequency transformers: validation on a prototype, IEEE Electrical Power and Energy Conference (EPEC), London, pp. 125-130, (2015).

[8] C. Ling, P. Shi, Y. Quan and T. Xiang, Research on transformer winding deformation and winding resistance, International Conference on Power Engineering \& Energy, Environment (PEEE 2016), ShangHai, China, pp. 1-7, (2016).

[9] T. Hong, D. Deswal and F. De Leon, An online data-driven technique for the detection of transformer winding deformations, IEEE Transactions on Power Delivery, 33: 2 (2018) 600-609.

[10] IEC 60076-1, "Power transformers - Part 1: General", (2000).

[11] IEEE Std. C57.12.90-2015, IEEE Standard Test Code for Liquid-Immersed Distribution, Power, and Regulating Transformers, (2016).

[12] W. G. Hurley, E. Gath and J. G. Breslin, Optimizing the AC resistance of multilayer transformer windings with arbitrary current waveforms, IEEE Transactions on Power Electronics, 15: 2 (2000) 369-376.

[13] R. Wang, F. Xiao, Z. Zhao, Y. Shen and G. Yang, Effects of asymmetric coupling on winding AC resistance in medium-frequency high-power transformer, IEEE Transactions on Magnetics, 50: 11 (2014) 1-4, (2014). 